\title{
A STUDY OF SERUM SIALIC ACID LEVELS IN PATIENTS WITH TYPE 2 DIABETES MELLITUS AND ITS RELATION TO LIPID PARAMETERS
}

\author{
Bindu Gopinathan Nair1, Fathima Beevi Osman²
}

${ }^{1}$ Associate Professor, Department of Biochemistry, Government Medical College, Thiruvananthapuram. ${ }^{2}$ Associate Professor, Department of Biochemistry, Government Medical College, Thiruvananthapuram.

\section{ABSTRACT}

\section{BACKGROUND}

Sialic acid, an acetylated derivative of neuraminic acid, is reported to be a marker of acute phase response. Elevated serum total sialic acid concentration may reflect the existence or activity of an atherosclerotic process.

The aims and objectives of the current study is to evaluate serum total sialic acid and various lipid parameters in patients with type 2 diabetes mellitus and to examine the relationship between serum total sialic acid with serum lipids which strongly influence the occurrence and advance of atherosclerosis.

\section{MATERIALS AND METHODS}

The study group consisted of 40 type 2 diabetic patients and 40 healthy controls between the age group of 20 and 60 years. The serum total sialic acids were analysed by the thiobarbituric acid assay of Warren. Fasting plasma glucose and fasting lipid profile were measured by commercially procured kits in a fully autoanalyser. Statistical analysis was done using SPSS version 22.0. Quantitative data was expressed as mean and SD and quantitative data for the two groups were compared with unpaired ' $t$ ' test. Association between total sialic acid and lipid parameters was assessed by Pearson correlation. $\mathrm{p}<0.05$ is considered significant.

\section{RESULTS}

Type 2 diabetic mellitus subjects had a higher total sialic acid levels compared with the controls. The mean serum total sialic level in non-diabetic controls was $55 \pm 4.47 \mathrm{mg} / \mathrm{dL}$ while in diabetic patients it was found to be $67.68 \pm 6.64 \mathrm{mg} / \mathrm{dL}$. Mean total sialic acid was found to be significantly higher than that of the control group $(\mathrm{p}<0.001)$. Also there was a significant difference in fasting blood sugar and lipid parameters between the two groups $(\mathrm{p}<0.05)$. Serum Total Sialic Acid correlated significantly with fasting blood sugar, total cholesterol, triglycerides, systolic and diastolic BP $(\mathrm{p}<0.001)$.

\section{CONCLUSION}

In this study, serum total sialic acid which is an inflammatory marker was increased in type 2 diabetes mellitus and significantly correlated with various lipid cardiovascular risk factors. Thus, it contributes to the cardiovascular risk.

\section{KEYWORDS}

Type 2 diabetes Mellitus (Type 2 DM), Total Sialic Acid, Coronary Artery Disease (CAD), Acute Phase Response.

HOW TO CITE THIS ARTICLE: Nair BG, Osman FB. A study of serum sialic acid levels in patients with type 2 diabetes mellitus and its relation to lipid parameters. J. Evolution Med. Dent. Sci. 2017;6(9):668-672, D0I: 10.14260/Jemds/2017/144

\section{BACKGROUND}

Atherosclerosis is the major cause of morbidity and mortality all over the world and its most common manifestation is Coronary Artery Disease (CAD) or Coronary Heart Disease (CHD). Diabetes mellitus patients have two times the incidence of CAD as compared to non-diabetics. Both type 1 and type 2 diabetes mellitus are powerful and independent risk factors for $\mathrm{CAD}$, stroke and peripheral arterial disease. Atherosclerosis accounts for virtually $80 \%$ of all deaths among diabetic patients. Prolonged exposure to hyperglycaemia is recognised as a major risk factor in the pathogenesis of atherosclerosis in diabetes. ${ }^{1}$

Financial or Other, Competing Interest: None.

Submission 21-12-2016, Peer Review 14-01-2017,

Acceptance 20-01-2017, Published 30-01-2017.

Corresponding Author:

Dr. Bindu Gopinathan Nair,

Associate Professor,

Department of Biochemistry

Government Medical College,

Thiruvananthapuram.

E-mail: drbindu2014@gmail.com

DOI: $10.14260 /$ jemds $/ 2017 / 144$

\section{(c) (i) $\$$}

Total serum sialic acid concentration has recently been shown to be a strong predictor of cardiovascular mortality in the general population. ${ }^{2}$ Because death from cerebrovascular and coronary heart disease is about two to four times as high in diabetes as in non-diabetic subjects, ${ }^{3}$ there is a strong case for examining serum sialic acid levels in people with diabetes and comparing these with concentration in normal subjects. Sialic acid is a generic term for the $\mathrm{N}$ - or $\mathrm{O}$-substituted derivatives of Neuraminic acid, a monosaccharide with nine carbon backbone. Sialic acid presents in the terminal sugar moiety of oligosaccharide side chains of various tissue glycoproteins and glycolipids, which act as cofactors of various cell surface receptors and these are found to be increased in various pathological states such as diabetes mellitus. Asian Indians are reported to have increased levels of acute phase proteins in the diabetic state itself even before the occurrence of any specific vascular complications. ${ }^{4}$ Sialic acid is a constituent of acute phase reactants and several acute phase proteins are elevated in diabetes mellitus. ${ }^{5}$ In human plasma a large quantity of sialic acid is found in orosomucoid, alpha antitrypsin, haptoglobin, ceruloplasmin, fibrinogen, complement proteins and transferrin. Some of these sialylated glycoproteins are acute phase reactants and such substances rapidly increase in concentration after the onset of an inflammation reaction or injury. ${ }^{6}$ Since sialic acid 
is negatively charged it stabilises glycoprotein conformation in cell surface receptor to increase cell rigidity. This enables signal recognition and adhesion to ligands, antibodies, enzymes and microbes. Since sialic acid is a component of cell membrane elevated levels of sialic acid may indicate excessive cell membrane damage to the cells of vascular tissue.

A patient with diabetes mellitus invariably presents with jeopardy in lipid metabolism which results in elevation of free fatty acid and triglycerides in blood. Several population based studies conducted across the world have clearly demonstrated that an elevated serum sialic acid level is linked directly to various cardiovascular risk factors like increased body mass index (BMI) and lipid profile levels in diabetic subjects suggesting the potential use of this parameter as a marker for cardiovascular disease in diabetes mellitus. ${ }^{7}$ The present concept is that atherosclerosis is an inflammatory disease and several population studies have pointed to serum sialic acid as a marker of inflammation in atherosclerosis. Since endothelial activation is in part mediated by dyslipidaemia it is possible that there may be an association between dyslipidaemia and serum sialic acid. The objective of this study is to evaluate serum total sialic acid and various lipid parameters in non-insulin dependent diabetes mellitus patients and to examine the relationship between sialic acid and serum lipids which may strongly influence the occurrence and advance of atherosclerosis.

\section{MATERIALS AND METHODS}

A case control study was conducted during June 2012 to September 2013. The study group was selected from the patients attending the Diabetic Clinic and Medical OP in Government Medical College Hospital, Thiruvananthapuram. The study group consisted of 80 individuals which included 40 diabetic patients and 40 healthy controls between the age group of 20 and 60 years. The diabetic group consisted of 23 males and 17 females.

The classification of subjects to Diabetic and Non-Diabetic groups was based on American Diabetic Association Criteria 2011. Pregnant ladies, patients on insulin, smokers, alcoholics, tobacco users, patients with hypertension, type 1 diabetes and other systemic illness were excluded from the study. This study was undertaken after approval by the institutional ethical committee according to the provisions of Helsinki declaration. A written informed consent was obtained from all participants. Blood pressure was recorded in the sitting posture using sphygmomanometer, from the right arm of the individual. Height was measured with the individual wearing no footwear. Weight was measured using Tanita fat monitor. Body mass Index (BMI) was calculated using the formula, $\mathrm{BMI}=$ weight in kilograms divided by the square of height in metres $\left(\mathrm{Kg} / \mathrm{m}^{2}\right)$.

\section{Collection of Blood Samples}

$6 \mathrm{~mL}$ of venous blood was drawn after 12 hours fasting and collected into two tubes. One tube containing sodium chloride and potassium oxalate for plasma glucose estimation and the other was a plain tube.

Plasma was separated from the first tube and used for measuring plasma glucose with a commercial Kit by GODPOD method on a fully autoanalyser by Transasia Biomed.
The blood in the plain tube was allowed to clot to separate serum. The serum was used to measure fasting lipid profile and serum total sialic acid using commercially procured kits in a fully autoanalyser by Transasia Biomed. High density lipoprotein (HDL) cholesterol was measured after precipitation of very low density lipoprotein (VLDL) and low density lipoprotein (LDL) cholesterol with phosphotungstic acid and magnesium. LDL Cholesterol was calculated by Friedewald formula.

LDL Cholesterol $=$ Total Cholesterol $-($ HDL cholesterol + Triglycerides/5)

Sialic acids were analysed by Thiobarbituric acid assay of Warren. ${ }^{8}$ Periodate oxidation of deoxy sugars was carried out in strong acid solution and a final coloured product formed by coupling of the product of oxidation and thiobarbituric acid. The periodate oxidation product was $\beta$-formyl pyruvic acid. This coloured compound was extracted in cyclohexanone and optical density was read in a spectrophotometer (Systronics) at wavelength $532 \mathrm{~nm}$ and $549 \mathrm{~nm}$.

\section{Statistical Analysis}

Statistical analysis was performed using SPSS version 22.0. Quantitative data were expressed as mean and standard deviation. Qualitative data were expressed as proportion. Quantitative data for the two groups were compared with unpaired $t$ test. One way ANOVA was used to compare the quantitative data for more than two groups. Association between two quantitative variables was analysed by Pearson Correlation. p value $<0.05$ was considered as statistically significant.

\section{RESULTS}

The findings in diabetic patients and control subjects are summarised in Table 1 . The mean age of the type 2 diabetic subjects is $47.55 \pm 5.09$ years and that of control group is $48.35 \pm 4.59$ years. Mean serum total sialic acid level in nondiabetic controls was $55 \pm 4.47 \mathrm{mg} / \mathrm{dL}$ while in diabetic patients it was found to be $67.68 \pm 6.64 \mathrm{mg} / \mathrm{dL}$. Increase in total sialic acid was found to be highly significant $(\mathrm{p}<0.001)$ (Figure 1). The mean fasting blood glucose level in nondiabetic controls is $80.88 \pm 11.95 \mathrm{mg} / \mathrm{dL}$ while in diabetic subjects it is $143.58 \pm 37.45 \mathrm{mg} / \mathrm{dL}$. The difference is statically significant $\mathrm{p}<0.001$. There was also a significant difference in the total cholesterol, triglycerides and LDL cholesterol and both systolic and diastolic blood pressure between the two groups $(\mathrm{p}<0.001)$.

HDL cholesterol was lower in the diabetic group compared to the control group. Of the 40 diabetic subjects, 10 (25\%) were treated by dietary adjustment alone, 13 (32.5\%) were treated by oral hypoglycaemic agents and 17 subjects $(42.5 \%)$ were treated with insulin (Table 2 and Figure 1). It was found that the difference in serum total sialic acid was not statistically significant.

Serum total sialic acid correlated significantly with fasting blood sugar, total cholesterol, triglycerides, systolic and diastolic BP $(\mathrm{p}<0.001)$ and LDL cholesterol $(\mathrm{p}<0.05)$. Serum TSA negatively correlated with HDL cholesterol $(\mathrm{p}<0.05)$ (Table 3). 


\begin{tabular}{|c|c|c|c|c|c|c|}
\hline \multirow{2}{*}{ Para-meters } & \multicolumn{2}{|c|}{ Case $(\mathrm{N}=40)$} & \multicolumn{2}{|c|}{ Control $(\mathrm{N}=40)$} & \multirow{2}{*}{$\mathbf{T}$} & \multirow{2}{*}{$\mathbf{p}$} \\
\hline & Mean & SD & Mean & SD & & \\
\hline Age in years & 47.55 & 5.09 & 48.35 & 4.59 & -.738 & .463 \\
\hline Body Mass Index $\left(\mathrm{Kg} / \mathrm{m}^{2}\right)$ & 24.95 & 2.48 & 24.55 & 2.73 & .686 & .495 \\
\hline Total Sialic Acid (mg\%) & 67.68 & 6.64 & 55.00 & 4.47 & 10.019 & $<0.001$ \\
\hline Fasting Blood sugar (mg\%) & 143.58 & 37.45 & 80.88 & 11.95 & 10.087 & $<0.001$ \\
\hline Total Cholesterol (mg\%) & 216.72 & 38.79 & 179.93 & 326.97 & 4.924 & $<0.001$ \\
\hline HDL Cholesterol (mg\%) & 45.75 & 8.39 & 49.53 & 8.68 & -1.978 & .051 \\
\hline Triglycerides (mg\%) & 160.28 & 81.68 & 99.23 & 26.36 & 4.499 & $<0.001$ \\
\hline LDL Cholesterol (mg\%) & 139.03 & 35.65 & 110.90 & 28.98 & 3.872 & $<0.001$ \\
\hline Systolic BP (mmHg) & 127.98 & 10.13 & 116.75 & 11.83 & 4.557 & $<0.001$ \\
\hline Diastolic BP (mmHg) & 82.85 & 6.39 & 77.80 & 5.90 & 3.673 & $<0.001$ \\
\hline \multicolumn{7}{|c|}{ Table 1. Summary of Data in Diabetic and Control Subjects } \\
\hline
\end{tabular}

\begin{tabular}{|c|c|c|c|c|c|}
\hline \multirow{2}{*}{$\begin{array}{c}\text { Treatment } \\
\text { Groups }\end{array}$} & \multirow{2}{*}{ N (\%) } & \multicolumn{2}{|c|}{ Total Sialic Acid (mg\%) } & \multirow{2}{*}{$\mathbf{F}$} & \multirow{2}{*}{$\mathbf{P}$} \\
\hline & & Mean & SD & & \\
\hline Diet & $10(25 \%)$ & 67.80 & 5.613 & \multirow{4}{*}{3.127} & \multirow{4}{*}{0.056} \\
\hline Oral hypoglycaemic & $13(32.5 \%)$ & 70.92 & 8.371 & & \\
\hline Insulin & $17(42.5 \%)$ & 65.12 & 4.649 & & \\
\hline Total & $40(100 \%)$ & 67.68 & 6.639 & & \\
\hline \multicolumn{6}{|c|}{ Table 2. Comparison of Total Sialic Acid levels in Different Groups of Treatment } \\
\hline
\end{tabular}

\begin{tabular}{|c|c|c|}
\hline Correlation of TSA (mg/dL) with other Parameters & $\begin{array}{c}\text { Pearson Correlation } \\
\text { R }\end{array}$ & P \\
\hline Age & .006 & .474 \\
\hline Body mass index & .081 & .614 \\
\hline Duration of illness in years & -.100 & $<0.001$ \\
\hline Fasting Blood sugar (mg\%) & $.647^{* *}$ & $<0.001$ \\
\hline Total Cholesterol (mg\%) & $.424^{* *}$ & $<45$ \\
\hline HDL Cholesterol (mg\%) & $-.225^{*}$ & $<0.001$ \\
\hline Triglycerides (mg\%) & $.404^{* *}$ & $<02$ \\
\hline LDL cholesterol (mg\%) & $.338^{* *}$ & $<0.001$ \\
\hline Systolic BP (mmHg) & $.479^{* *}$ & $<0.001$ \\
\hline Diastolic BP (mmHg) & $.382^{* *}$ & \\
\hline Table 3. Correlation of TSA (mg/dL) with Other Parameters \\
\hline
\end{tabular}

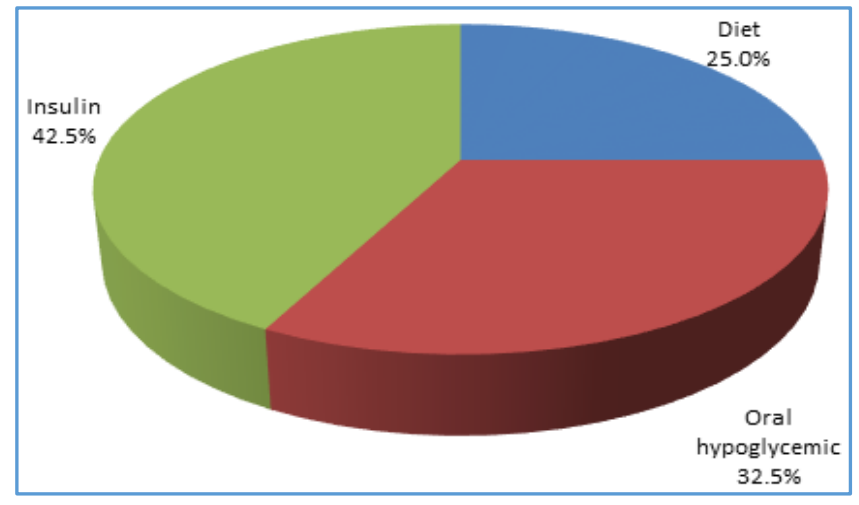

Figure 1. Distribution of Treatment Groups

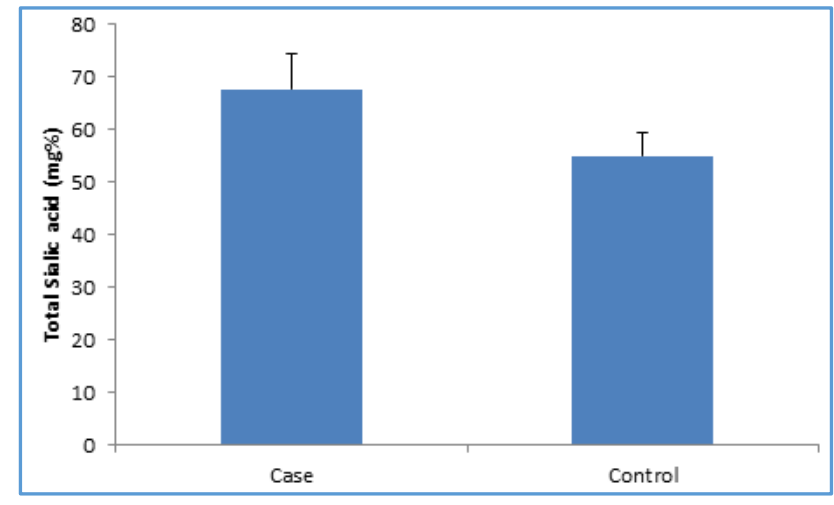

Figure 2. Comparison of Total Sialic Acid between Cases and Controls 

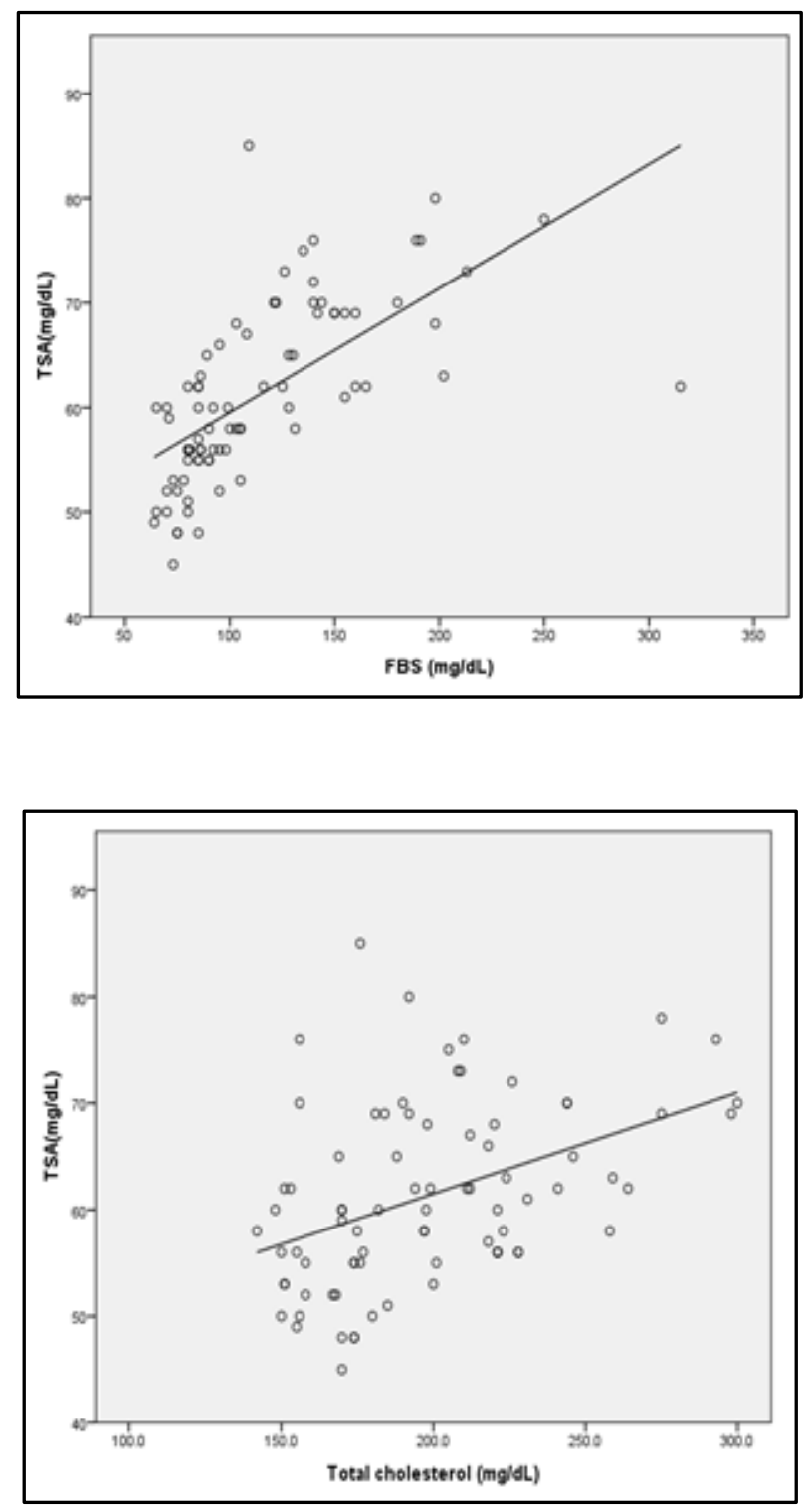

Figure 3. Correlation of Total sialic acid with other Parameters

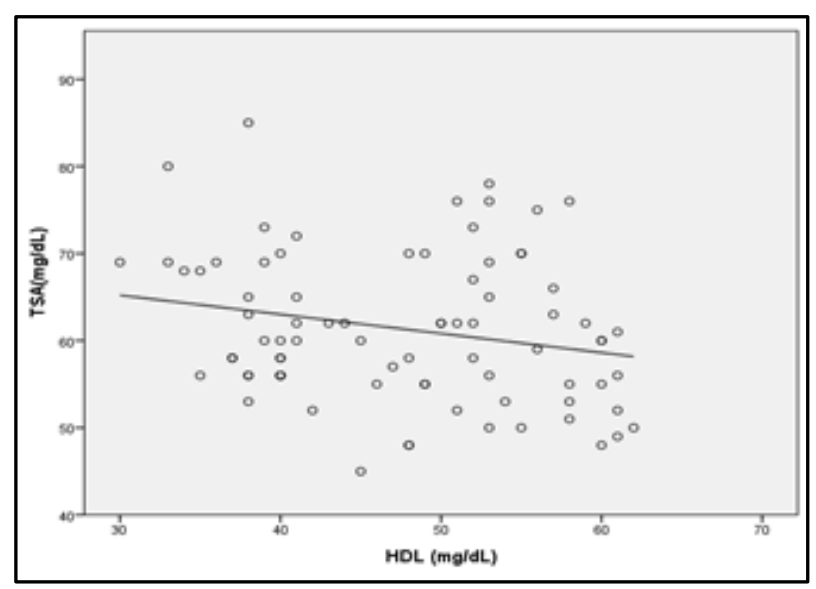

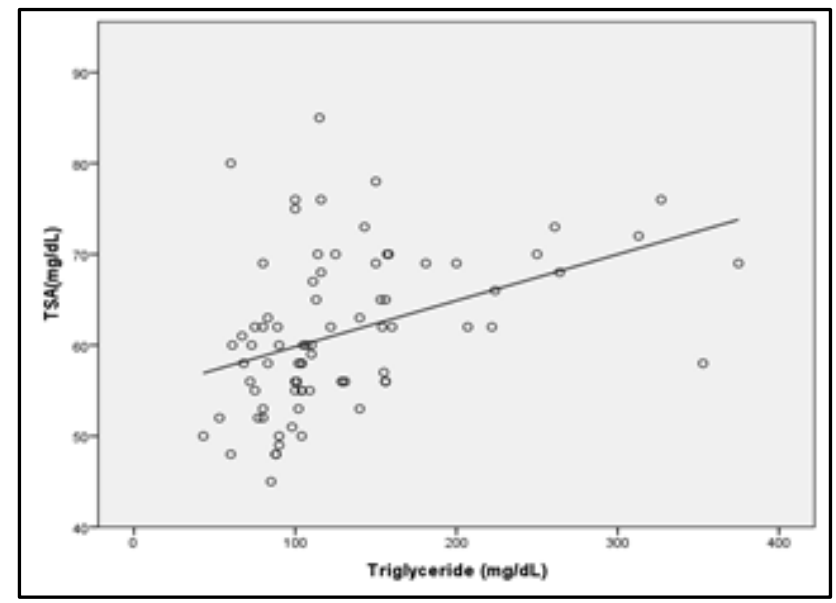

TSA - Total Sialic acid

\section{DISCUSSION}

Coronary artery disease (CAD) remains a major health problem in every country. CAD is assuming epidemic proportions in the Indian sub-continent. Individuals with diabetes have greatly increased CAD risk compared with nondiabetic individuals. ${ }^{9}$ In this study, various lipid and non-lipid parameters were studied in diabetes which is a high risk group of CAD. The lipid parameters studied were total cholesterol, triglycerides, LDL and HDL cholesterol. The nonlipid parameters studied were total sialic acid, fasting blood sugar, body mass index (BMI) and BP. The mean Total Sialic Acid in the control group was $55.0 \pm 4.47 \mathrm{mg} \%$ which is similar to the results of Singh and Ramraj, 1967. Their study showed serum total sialic acid level to be $56 \pm 5 \mathrm{mg} \%$ in normal Indian adults by Thio Barbituric Acid method. ${ }^{10}$

Serum total sialic acid was significantly increased in the diabetic group compared to the control group $(\mathrm{p}<0.001)$. This is similar to the earlier studies by Balu Mahendran et al, 2013; Ekin et al, 2003; Melidonis et al, 1988; Crook et al, 1993.11 - 13 Elevated level of serum sialic acid is a risk factor for overall mortality in type 2 diabetes mellitus patients. Serum sialic acid is a marker of acute phase response.14, 15 There is an association between type $2 \mathrm{DM}$ and increased total sialic acid, which is possibly due to generalised endothelial dysfunction or macrovascular disease. This is either through loss of sialic acid containing glycoproteins from vascular cells into the blood stream or through an acute phase response. Type $2 \mathrm{DM}$ may be considered as acute phase disease because the serum levels of acute phase proteins have increased without tissue complications.

In our study, we found higher sialic acid levels in diabetic patients treated with oral hypoglycaemic agents compared to those treated with diet alone or insulin, Table 2. This is similar to study by other workers. However, ours was also a study of a relatively small group of patients. So it would be unjustified to draw conclusions about the effects of type of treatment on sialic acid concentrations. Therefore, study involving a larger group of type 2 DM subjects is required. Furthermore, a good correlation was observed between sialic acid and important cardiovascular risk factors such as cholesterol and triglyceride $(\mathrm{p}<0.001)$ and LDL $(\mathrm{p}<0.05)$. This is similar to the study by other workers. ${ }^{16}$ The correlation between total sialic acid and serum lipids may be due in part to sialylation of lipoproteins. ${ }^{17}$ The dyslipidaemia, common in 
type $2 \mathrm{DM}$, is also a feature of natural and experimental acute phase reactions. ${ }^{18} \mathrm{~A}$ study by Lindberg et al, 1993 proves that serum sialic acid, which can be considered as an integrated marker of the levels of several acute phase proteins, predicts CHD. 19

Russel Ross 1999 has described that the lesion of atherosclerosis represents a series of highly specific cellular and molecular responses that can best be described in aggregate as an inflammatory disease. ${ }^{20}$ Activation of innate immunity (Low grade inflammation) is a risk factor for cardiovascular disease mortality in type 2 DM independently of other known risk factors.

Activation of the innate immune system predicts type 2 $\mathrm{DM}$, it may be a common antecedent of type $2 \mathrm{DM}$ and Cardiovascular disease. ${ }^{21}$ Thus, chronic activation of the innate immune system which produces the acute phase response has been postulated to lead to insulin resistance, abnormalities in glucose intolerance and lipid metabolism as well as to endothelial activation, resulting in increased vascular tone and atherosclerosis. ${ }^{18}$

\section{CONCLUSION}

Since inflammation is involved in the pathogenesis of diabetes and atherosclerosis, measurement of inflammation sensitive markers may be useful for assessment of the cardiovascular risk in diabetic patients. In this study, serum total sialic acid which is an inflammatory marker is increased in diabetes and is significantly correlated with various lipid cardiovascular risk factors. In conclusion, this preliminary study shows that serum sialic acid may be important in diabetes and should be studied in larger groups of diabetic patients.

\section{REFERENCES}

[1] Grundy SM, Benjamin IJ, Burke GL, et al. Diabetes and cardiovascular disease: a statement for health care professionals from the American Heart Association. Circulation 1999;100(10):1134-46.

[2] Lindberg G, Eklund GA, Gullberg B, et al. Serum Sialic acid concentration and cardiovascular mortality. BMJ 1991;302(6769):143-6.

[3] Crook MA, Tutt P, Pickup JC, et al. Elevated serum sialic acid concentration in NIDDM and its relationship to blood pressure and retinopathy. Diabetes care 1993;16(1):57-60.

[4] Deepa R, Rema M, Mohan V. Lack of association between serum sialic acid levels and retinopathy in type 2 diabetic patients. Diabetes Res Clin Pract 1998;41(3): 165-9.

[5] Kumar SP, Latha JM, Amarendra M, et al. A Study of serum sialic acid in non-insulin dependent diabetes mellitus. Indian Journal of Basic and Applied Medical Research 2015;4(4):612-9.
[6] Ponnio M, Alho H, Nikkari ST, et al. Serum sialic acid in a random sample of general population. Clin Chem 1999;45(10):1842-9.

[7] Crook M, Lumb P, Andrews V, et al. Serum total sialic acid, a reputed cardiovascular risk factor and its relationship to lipids, plasma fasting insulin, blood pressure and body mass index in normal individuals. Clin Sci (Lond) 1998;95(1):53-7.

[8] Warren L. The thiobarbituric acid assay of sialic acids. J Biol Chem 1959;234(8):1971-5.

[9] Howard BV, Lee ET, Cowan LD, et al. The rising tide of cardiovascular disease in American Indians. The strong heart study. Circulation 1999;99(18):2389-95.

[10] Singh R, Ramaraju B. Serum sialic acid values in healthy Indian adults. Indian J Med Res 1967;55:63.

[11] Mahendran BK, Gnanadesigan E, Rekhakumari D, et al. Evaluation of sialic acid levels in patients with Type 2 diabetes mellitus. IOSR Journal of Dental and Medical Sciences 2013;5(1):33-6.

[12] Ekin S, Meral I, Gunduz H, et al. A comparative study of total protein and total lipid associated serum sialic acid levels in patients with type 2 diabetes mellitus. J Clin Lab Anal 2003;17(4):124-6.

[13] Melidonis A, Tournis S, Hraklioti S, et al. Serum Sialic acid concentration and diabetic nephropathy in Type 2 diabetes mellitus. Diabetologica croatica 1988;27-41.

[14] Taniuchi K, Chifu K, Hayashi N, et al. A new enzymatic method for the determination of sialic acid and its application as a marker of acute phase reactants. Kobe J Med Sci 1981;27(3):91-102.

[15] Pick Up JC, Mattock MB, Chusney GD, et al. Non Insulin Dependent Diabetes Mellitus as a disease of the innate immune system: association of acute-phase reactants and interleukin-6 with metabolic syndrome $\mathrm{X}$. Diabetologia 1997;40(11):1286-92.

[16] Subzwari J, Qureshi MA. Relationship between Sialic acid and microvascular complications in Type 2 diabetic mellitus. Biomedica 2012;28:130-3.

[17] Wakabayashi I, Sakamoto K, Yoshimoto S, et al. Relation of serum sialic acid to lipid concentrations. BMJ 1992;305(6853):562-3.

[18] Pickup JC, Crook MA. Is type 2 diabetes mellitus a disease of the innate immune system? Diabetologia 1998;41(10):1241-8.

[19] Lindberg G, Rastam L, Gullberg B, et al. Serum concentration of total sialic acid and sialoglycoproteins in relation to coronary heart disease markers. Atherosclerosis 1993;103(2):123-9.

[20] Ross R. Atherosclerosis and inflammatory disease. N Eng J Med 1999;340(2):115-26.

[21] Schmidt MI, Duncan BB, Sharrett AR, et al. Markers of inflammation and prediction of diabetes mellitus in adults. (Atherosclerosis risk in communities study): a cohort study. Lancet 1999;353(9165):1649-52. 